ARTIKEL AUDIT STRUKTUR DATA BERBASIS MY SQL BERBASIS WEB

\author{
Nama Mahasiswa \\ WINARIYANI \\ 175100007 \\ Universitas Mitra Indonesia, Sistem Informasi \\ Mahasiswa@umitra.ac.id
}

\title{
PENGUJIAN TEKNOLOGI REMOTE KONTROL DENGAN MEDIA INFRA MERAH, GELOMBANG RADIO, INTERNET, DAN SALURAN TELEPON
}

\begin{abstract}
ABSTRAK
Remote control telah banyak dikembangkan dengan memanfaatkan berbagai media transmisi. Diantaranya adalah remote control dengan memanfaatkan media infra merah, gelombang radio, internet dan saluran telepon. Sistem remote control melalui saluran telepon memiliki keunggulan dalam hal jarak jangkauan dan kepraktisan dibanding media lainnya.

Hadirnya handphone yang telah dikenal dan digunakan banyak orang, yang mampu melakukan komunikasi dimanapun mereka berada tanpa dibatasi oleh ruang dan rentang panjang kabel bisa menjadi solusi bagi kebutuhan pengendalian jarak jauh.. Salah satu fungsi handphone yang paling populer ialah untuk mengirim dan menerima SMS. SMS ini sangat cocok digunakan untuk sistem pengontrol wireless real time.
\end{abstract}

Kata Kunci: Serial Handphone, Mikrokontroler, Kontrol Jarak Jauh 


\section{A. PENDAHULUAN}

Pada saat ini pengendalian on/off berbagai piranti listrik kebanyakan masih dikendalikan secara manual dengan menekan tombol saklar on/off.

Perkembangan gaya hidup dan dinamika social saat ini menunjukkan semakin pentingnya kepraktisan dan efisiensi menyebabkan kebutuhan untuk mengendalikan berbagai piranti listrik tidak hanya dilakukan secara manual yang mengharuskan kita berada didepan piranti listrik tersebut dan menekan tombol saklar on/off untuk mengaktifkannya tetapi bisa juga dilakukan dari jarak jauh (remote control). Teknologi remote control telah banyak dikembangkan dengan memanfaatkan berbagai media transmisi. Beberapa diantaranya adalah remote control dengan memanfaatkan media infra merah, gelombang radio, internet dan saluran telepon.Sistem remote control melalui saluran telepon memiliki keunggulan dalam hal jarak jangkauan dan kepraktisan dibanding media lainnya. Hadirnya Telepon bergerak (seluler) atau handphone yang telah dikenal dan digunakan banyak orang, yang mampu melakukan komunikasi dimanapun mereka berada tanpa dibatasi oleh ruang dan rentang panjang kabel bisa menjadi solusi bagi kebutuhan pengendalian jarak jauh (remote contro) seperti yang telah diuraikan diatas. Salah satu fungsi handphone yang paling populer ialah untuk mengirim dan menerima SMS. SMS ini sangat cocok digunakan untuk sistem pengontrol wireless real time karena kecepatan pengiriman datanya, efisiensi dan luasnya jangkau an, namunkelebihan handphone dengan fasilitas SMS-nya ini masih perlu dihubungkan ke suatu perangkat kontrol untuk dapat melakukan pengendalian on/off piranti listrik dari jarak jauh. Saat ini salah satu perangkat kontrol yang cukup praktis dan banyak digunakan adalah 
mikrokontroler yaitu sebuah chip yang berfungsi sebagai pengontrol rangkaian elektronik dan dapat menyimpan program didalamnya. Kelebihan utama mikrokontroler ialah tersediannya RAM dan peralatan I/O pendukung sehingga memiliki ukuran yang sangat ringkas dan lebih leluasa untuk dihubungkan dan melakukan pengontrolan terhadap perangkat lain.

Dalam penelitian ini spesifikasi alat yang dirancang adalah sebagai berikut :

a) Komunikasi antara handphone dengan mikrokontroler menggunakan komunikasi serial dengan standar RS232.

b) Menggunakan pengendali mikro buatan atmel yaitu AT89S51.

c) Menggunakan perintah ATCommand untuk mengakses handphone melalui port data serialnya.

d) Kontrol jarak jauh menggunakan handphone mealui jaringan GSM dengan operator

(indosat

m3/telkomsel/excelcom).

e) Menggunakan handphone jenis

Siemens

(ME,S, C2x $, . .3 x, . .4 x, . .5 x$ ) yang support AT-Command. Dapat mengontrol on/off 8 piranti listrik. Tujuan yang ingin dicapai dari penelitian ini untuk merancang dan merealisasikan antarmuka antara handphone dengan mikrokontroler untuk dapat melakukan control jarak jauh. Dan dapat bermanfaat dalam memahami komunikasi antara handphone dengan pengendali mikro sebagai sarana pengendali jarak jauh.

\section{B.TINJAUAN PUSTAKA}

Remote control menggunakan sinyal infra yang setiap tombol pada remote control mengeluarkan sinyal infra yang berbeda-beda. Sinyal-sinyal tersebut dapat ditangkap penerima sinyal untuk dikodekan lebih lanjut. Sinyal-sinyal yang dikirim biasanya dalam bentuk termodulasi. Bentuk modulasi 
berbeda-beda tergantung pada pembuat remote. Remote control (Gunawan,2000).

\section{STUDI KASUS}

1) Komunikasi Serial

Komunikasi serial ialah pengiriman data secara serial yaitu data dikirim satu per satu secara berurutan, dikenal dua cara komunikasi data secara serial, yaitu komunikasi data secara sinkron dan komunikasi data secara asinkron. Pada komunikasi data serial sinkron, clock dikirimkan bersama-sama dengan data serial, sedangkan komunikasi data serial asinkron, clock tidak dikirimkan bersama data serial, tetapi dibangkitkan secara sendiri-sendiri baik pada sisi pengirim (transmitter) maupun pada sisi penerima (receiver). Komunikasi antara handphone dengan mikrokontroler yang digunakan dalam skripsi ini adalah secara serial asinkron yang bersifat fullduplex, artinya port serial bisa mengirim dan menerima pada waktu yang bersamaan. berdasarkan standar RS232 dengan level tegangan untuk RS232. Handphone memiliki level tegangan yang berbeda dengan level tegangan TTL ataupun RS232, tetapi untuk kompatibilitas handphone agar bisa terkoneksi dengan PC guna berbagai keperluan maka pada tiap tipe ponsel tersedia kabel data yang compatible dengan standar RS232 sebagai interface untuk koneksi ke PC, untuk konfgurasi port data tipe handphone yang digunakan yaitu Siemens S45.

\section{2) Interface RS232}

a. Interface adalah suatu perangkat keras (hardware) yang menguhubungkan dua elemen pemrosesan data yang berbeda. Interface dapat dipakai untuk menghubungkan perangkat keras yang satu dengan perangkat keras yang lain. RS232 adalah suatu perangkat Serial Asynchronous Communication Interface Adapter yang 
diperkenalkan oleh EIA ( electronic industries adapter ), RS adalah singkatan dari Recommended Standard.

3) Menghubungkan TTL ke RS 232IC digital, termasuk mikrokontroler, umumnya bekerja pada level tegangan TTL, yang dibuat atas dasar tegangan catu daya +5 Volt.

a. Rangkaian input TTL menganggap tegangan kurang dari 0,8 volt sebagai level tegangan ' 0 ' dan tegangan lebih dari 2,0 volt dianggap sebagai level tegangan ' 1 '. Level tegangan ini sering dikatakan sebagai level tegangan TTL.

b. Untuk menjamin output bisa diumpankan ke input dengan baik, tegangan output TTL saat level ' 0 ' dijamin lebih rendah dari 0,4 volt, atau 0,4 lebih rendah dari tegangan yang dituntut oleh input TTL. Sedangkan tegangan output TTL pada saat level ' 1 ' dijamin lebih tinggi dari 2,4 volt atau 2,4 volt lebih tinggi dari tegangan yang dituntut oleh input TTL.

4) Konektor Dan Jenis Sinyal RS 232

Selain mendeskripkan level tegangan seperti yang dibahas diatas, standard RS232 menentukan pula jenis-jenis sinyal yang dipakai untuk mengatur pertukaran informasi antara DTE dan DCE, semuanya terdapat 24 jenis sinyal tapi yang umum dipakai hanyalah 9 jenis sinyal. Konektor yang dipakai pun ditentukan dalam standard RS232, untuk sinyal yang lengkap dipakai konektor DB25, sedangkan konektor DB9 hanya bisa dipakai untuk 9 sinyal yang umum dipakai.

5) Mikrokontroler AT89S51

Pada penelitian ini digunakan IC pengendali mikro AT89S51 keluaran atmel yang merupakan sebuah mikrokomputer 8 bit berbasis CMOS.

\section{DISKUSI}

Remote control? Apa Itu?

A: Zaman sekarang begitu canggih, begitu juga dengan 
munculnya remote control, tetapi masih banyak yang bingung apa sih remote control?

B. Remote control itu salah satu komponen dalam sebuah alat elektronik yang digunakan untuk mengoperasikan sebuah mesin dari jarak jauh.

C. Banyak manfaat yang ditimbulkan dengan adanya remote control, misalnya kita dapat mematikan atau menghidupkan TV dari jarak jauh.

\section{E. KESIMPULAN}

Secara keseluruhan mulai dari perancangan, realisasi dan pengujian sistem, dapat ditarik beberapa kesimpulan dari hasil penelitian ini antara lain :

1) Secara keseluruhan alat komunikasi antara handphone dengan mikro secara serial ini dapat bekerja dan berfungsi sebagaimana yang diharapkan sehingga dapat dimanfaatkan sebagai alat pengontrol jarak jauh. Alat ini dapat melakukan pengontrolan ketika terdapat SMS di memory smarthphone.

2) Handphone yang bisa digunakan hanya yang support dengan ATCommand.

3) Kabel data handphone yang digunakan harus yang original atau yang bisa berkomunikasi secara fullduplex untuk mengirim sekaligus menerima data dari dan ke mikro.

4) Alat ini dapat melakukan pengontrolan jarak jauh hingga beratus-ratus bahkan beribu-ribu $\mathrm{km}$ tergantung luasnya jaringan GSM.

5) Cepat atau lambat sampainya SMS sangat tergantung pada keadaan jaringan dari masing-masing service centre.

6) Biaya yang digunakan untuk melakukan pengontrolan cukup murah. 


\section{F. REFERENSI}

[1] A.S Putra And O.M. Febriani, "Knowledge Management

Online Application In Pdam Lampung Province," in Prosiding International Conference On Information Technology And Business (ICITB),2018,Pp.181-187.

[2] FEBRIANI, Ochi Marshella; PUTRA,Arie Setya. Sistem Informasi Monitoring Inventori Barang Pada Balai Riset Standardisasi Industri Bandar Lampung. Jurnal Informatika,2014,13:1:90-98

[3] 9).2018 Artikel Struktur Data,Audit dan Jaringan Komputer, Retr1ieved from osf.io/3uq8w.

[4] Hariyanto,Bambang. 2000. Struktur Data. Bandung: CV. Informatika. Modul Dasar Struktur Data "BSI".

[5] Desphande P.S.,O.G. Kakde
(2004). C dan Data Structures.

Charles River Media, Inc. Massachusetts. 
